\title{
CURRENT ISSUES OF PERSONAL DATA PRIVACY IN MARKETING
}

\author{
[Aktuální otázky ochrany osobních údajů v marketingu]
}

\author{
Lenka Hanáková ${ }^{1}$ \\ ${ }^{1}$ Tomas Bata University in Zlin, Faculty of Management and Economics, Mostni 5139, 76001 Zlín \\ Email: lhanakova@utb.cz
}

\begin{abstract}
Data privacy is a current issue that must be addressed by all entities when handling personal data. Although the General Data Protection Regulation (GDPR) has been effective for more than two years, it still poses challenges to businesses, especially small and medium-sized enterprises (SMEs). The aim of the paper was therefore to find out what SMEs in the Czech Republic in terms of their running consider and perceive as contemporary data privacy issues in marketing and why, because marketing is one of the areas that have been fundamentally affected by GDPR. The particular objective of this contribution was to introduce brief conclusions of the focus group with the managers of marketing activities, employees in charge of marketing issues and GDPR, or owners of SMEs. This focus group was the second in a row and its aiming corresponded to the declared goal of the paper. The chosen research method represents a necessary and important pre-research phase for the future planned qualitative and quantitative research. The main findings and conclusions showed that the issue of GDPR and the related necessity to ensure the protection of customers' personal data is a topic that still actively employs business entities and presents persistent challenges for them.
\end{abstract}

Keywords: data privacy, GDPR, marketing, SMEs.

JEL classification: M31, K19

Received: 30.9.2020; Reviewed: 28.10.2020; 17.1.2021; Accepted: 27.1.2021

\section{Introduction}

General Data Protection Regulation (hereinafter referred to as GDPR) is European legislation that has been in force for more than two years and whose existence affects not only business entities and public institutions, but also individuals. The adoption of this legislation with direct effect in all EU Member States was a response to the rapidly changing milieu and technological developments associated with the flow of large amounts of data concerning individuals. GDPR is therefore a legal framework for the protection of personal data that is directly applicable throughout the EU. It provides protection for the rights of EU citizens against unauthorized use of their personal data. However, it should be emphasized that there was no legal vacuum in terms of personal data protection before GDPR. Within the EU, there was legislation on the protection of personal data in the form of a Directive 95/46/EC, however, its form was no longer sufficient precisely in view of rapid technological progress.

Since 2016, when GDPR was adopted, a number of articles on this issue have been published from various perspectives. These were both academic and popular science articles. In addition, the issue of GDPR is a very broad topic that can really be viewed from different angles. It should be emphasized that the position of GDPR is in some way specific. The reason is obvious - it has an impact on any entity that collects or processes Europeans' personal data, including non-EU businesses operating in the European market. A certain uniqueness of GDPR also lies in the fact that it affects business entities across segments and sectors. It also has an impact on those entities that, for example, monitor or analyze user behavior on the web, when using various applications or smart technologies.

The perception of GDPR by many businesses as a concern and a challenge at the same time is probably due to the fact that it is legislation written in legal language that is specific in many 
respects and may pose some problems in interpretation and subsequent application, especially by those who do not have a legal education. In addition, like any other piece of legislation, rights and obligations are always formulated in general terms that may not always be unambiguous. This can create a space for uncertainty and different interpretations and understandings, which is of course undesirable.

Business entities will not learn from GDPR exactly what to do and how to do it. GDPR does not provide them with clear and precise guidance on what steps to take to comply. The decision on what concrete steps to take to ensure full compliance with GDPR is always up to each individual business entity. Undoubtedly, this decision is also linked to the responsibility for compliance with GDPR and for its subsequent maintenance. From this point of view, a number of articles on GDPR compliance are only a possible first general information base leading to ensuring compliance, but in no case, they can serve as a specific solution for individual business entities. The reason is that every business entity is different. This difference may lie, for example, in the nature and amount of personal data processed, the risk of processing, the size of the business entity, the nature of the activity performed, whether and to what extent it is focused on customers, etc.

The aim of this paper is to present the results of the focus group, which was conducted in the second half of August and which was focused on finding out what small and medium-sized business entities in the Czech Republic consider and perceive with regard to their running as current issues of personal data privacy in marketing. In this sense, the focus group represents a pre-research part of future qualitative and quantitative research focused on changes in the approach of business entities to the protection of customers' personal data after the effectiveness of GDPR.

The structure of the article is as follows. Firstly, a basic literature review and theoretical background are performed. Secondly, the methodology is explained. Thirdly, the results are presented. Fourthly, a short discussion is included. Finally, a conclusion is given.

\section{Literature review and theoretical background}

\subsection{Personalization in marketing}

Although GDPR has been effective for a little over two years, the literature review shows that issues related to data privacy in marketing have been addressed by many authors in the past. Martin et al. (2017), for example, point to the importance and significance of customer data. In the case of their thoughtful use, they can mean a certain benefit for customers, e.g. in the form of more targeted and more relevant marketing communication in relation to a specific customer, as well as price discounts, free services, or offering personalized products and services. In other words, it is mentioned the possible relationship between information about customers and their quality and content and the activities of marketers who are able to effectively use such information so that the customers can feel for themselves some benefit, for example in the form of marketing communication that will not be annoying and will be perceived by customers as interesting and beneficial for them.

Similarly, Aquirre et al. (2015) point out that the reason why business entities choose to collect data on their customers' online behavior is to use it to create personalized service offerings. At the same time, however, they draw attention to the related paradox, namely that on the one hand greater personalization in relation to the customer may lead to an increase in perceived relevance of the service by the customer and thus to greater acceptance by him or her, on the 
other hand, it may at the same time mean an increase in customer-perceived vulnerability and, as a result, lower acceptance of such a personalized offer of a service or good. The authors state that personalization can be not only an effective marketing strategy but also ineffective, depending on the context. At the same time, however, they also admit that it is unclear what effect different data collection methods have on the mentioned paradox. However, this knowledge could certainly be beneficial for businesses, as they could only consciously and purposefully use such marketing communication that would minimize, or at best avoid, the negative effects of personalization.

Tam et al. (2006) describe personalization as a marketing strategy that is characterized by a customer focus. Emphasis is placed on several factors, namely the right timing, the right targeting, the right content of the message. The goal is to maximize both current and future business opportunities.

Many authors deal with personalization in terms of its benefits. They talk about the benefits and advantages associated with personalization for both the business entities implementing personalization in relation to the customer, as well as for customers to whom the personalized message is targeted (Rossi et al. 1996; Zhang and Wedel 2009; Murthi and Sarkar 2003; Rust and Chung 2006; Vesanen 2007; Ansari and Mela 2003).

Schultz (2018) comments on the results of a survey conducted by Evergage and Researchscape on personalization with 300 businesses participating in the survey. Entrepreneurs give several reasons for using personalization, which they perceive as an advantage for themselves. This includes, for example, a higher conversation rate, better customer experience, or increased engagement. The survey also showed that $92 \%$ of surveyed businesses use personalization and $98 \%$ perceive it as a very effective means of developing relationships with customers.

For business entities that want to adapt their marketing activities as much as possible to the needs of their customers, it is absolutely crucial to learn as much as possible about their customers. They can only achieve this by collecting information and data about them. As reported, for example, by Murthi et al. (2003) or Sundar et al. (2010), different strategies are used by businesses to achieve this goal, and the difference between them may be, for example, whether and to what extent consumers are aware of how and when information about them is collected. From this point of view, one can distinguish between overt and covert strategies. The difference between them is clear. In the case of the application of overt data collection strategies, consumers are informed of this fact. On the contrary, in the case of the application of a covert data collection strategy, this fact remains secret for consumers. In this context, however, e.g. Verhoef et al. (2010) acknowledge that this ignorance of data collection on the part of the customer may mean an advantage for the business entity in the form of obtaining unbiased customer data, which on the part of the business entity may contribute to better customer knowledge and consequently better adaptation of services to this customer.

\subsection{Selected theoretical bases regarding privacy in the context of marketing}

In this part, some theoretical background concerning privacy will be very briefly introduced.

Caudill and Murphy (2000) or Maignan and Ferrell (2004) deal with Social Contract Theory in the context of marketing. They state that business entities carry out marketing activities in relation to customers in such a way in order to achieve not only an increase in future exchanges but also to support the creation of long-term relationships. Business entities are expected to adapt their procedures to meet stakeholders' data protection rules. However, if business entities 
will not be able to ensure the protection of customer privacy, i.e. there is a certain failure on their part in this respect, the result is a breach of the social contract. In this sense, it can be said that the principles of personal data protection (in other words - privacy policies within organizations) are necessary but they are by no means sufficient condition in terms of mutual exchange between the organization and the customer. However, customers believe that it is possible to talk about compliance with the social contract if business entities provide customers with either greater value through personalized offers or monetary compensation.

Another theoretical approach to marketing is Justice Theory, which is addressed, for example, by Rawls (1971), Ashworth et al. (2006), or Vail et al. (2008). This theory is viewed from two aspects, namely distributive justice and procedural justice. In the context of marketing exchange, distributive justice is understood as the consumer-perceived justice that results from the exchange. The business entity must specify procedures to protect consumer privacy (in this sense, it is a matter of procedural justice). These are procedures concerning both fair access to and use of customer information. From the customer's point of view, such policies and procedures created regarding personal data and its use can help reduce customers' privacy concerns if they are perceived as fair by them. In such a case, they can also support the customer's trust in relation to the business entity and the related willingness of the customers to make their data available. The mentioned aspect of distribution justice can be of benefit to consumers, for example in the form of offers tailored to the needs of the customer, better interaction between the customer and the business entity, or access to free services. However, an important consideration is, in particular, that if distribution justice is perceived by customers as high-level, such customers are more likely to be willing to give up part of their privacy and also to tolerate moderate breaches of privacy due to highly targeted advertising (meaning in a situation where they have not given their prior consent).

Emerson (1976), Chelappa et al. (2005), White (2004), and Schumann et al. (2014) deal with the so-called Social Exchange Theory. The basis of this theory is a two-way process that leads to exchange. This bilateralism includes other aspects, namely the aspect of cross-compliance and the aspect of reward. In other words, before consumers decide to participate in a marketing exchange, they rationally consider a number of circumstances, such as the costs associated with the exchange, the benefit that the exchange will bring them, possible competitive options - i.e. whether it is not better to implement the exchange process with another business entity. Therefore, if consumers evaluate that the benefits to them from a given exchange are greater than the costs they perceive, then they are willing to provide their personal data according to this theory. This provision of data is therefore a conscious response on the part of consumers to the benefit that the business entity is willing to provide them in the exchange. Consumers benefiting from the exchange can be for example marketing offers tailored to the customer or the provision of a free service. If there is trust on the part of the consumer in relation to the business entity, the willingness of the consumer to participate in the marketing exchange is further strengthened.

Issues of trust and perceived equality are the focus of the Power-Responsibility Equilibrium Theory, which is addressed by, for example, Murphy et al. (2005), Norberg et al. (2014), Lwin et al. (2007) or Xu et al. (2012). According to this theory, if one of the partners is in a stronger position in a mutually existing relationship, then there is a social obligation on his part to behave in such a way that there can be an environment in which both parties, including the weaker party in the relationship, feel equality and trust. In marketing exchange relations, this weaker entity is the consumer. If consumers perceive a power imbalance in a relationship, they will act defensively, such as not disclosing their personal information or failing to provide the business 
entity with true information and data about themselves. Customer privacy concerns can be alleviated by strong privacy policies as well as by the extent to which the consumers feel the possibility of control, but ultimately, it will also depend on the nature of the information that the business entity seeks, such as whether it is sensitive data.

Brehm (1966), Bleier et al. (2015), White et al. (2008) deal with Reactance Theory. The essence of this theory is that the subjects, in the case of marketing exchange specifically the consumers, react in a certain way when they feel that someone or something takes away from them possibilities or limits the range of alternatives in terms of freedom of their decision. If the consumer is under strong pressure to act in a certain way, reactance may occur -i.e. on the part of the consumer an attitude will be taken or strengthened which is completely contrary to what was originally observed and what the business entity wanted to achieve. Resistance to persuasion is also increasing. It has been found that when consumers perceive the existence of freedom of choice and when they perceive the possibility of control, there is an improvement in meeting the marketing objectives pursued by the business entities, such as purchase, data disclosure by consumers, or click-through. Otherwise, i.e. if consumers perceive freedom of choice or control as limited or even completely unavailable, their reaction may be reflected in a reduction in the expected marketing results on the part of business entities. It was found that privacy concerns increase reactance, and conversely, perceived trust, the credibility of a business entity, or the value of the marketing benefits of a marketing exchange can reduce reactance.

It can be seen from these theoretical approaches that the issue of privacy in connection with marketing is a topic that is addressed by many authors for a long time. The marketing exchange between the consumer and the business entity includes a number of questions and approaches on how to look at them. GDPR seeks to provide consumers with protection regarding their personal data. Therefore, it contains a number of obligations and principles that business entities must respect in the implementation of marketing activities and in general in customer relationship management.

The goal of business entities is profit. Therefore, they strive to reach customers with such an offer and in such a way as to make them to purchase a certain product or service. As the literature and theoretical review show, personalization is a way to tailor the offer to the needs and interests of the customer so that both the business entity and the customer gain benefits from the mutual marketing exchange. The question is to what extent GDPR is an obstacle for businesses in this regard. The aim of this paper is therefore to find out what SMEs in the Czech Republic consider and perceive with regard to their running as current data privacy issues in marketing and why.

\section{Methodology}

\section{Reasons for choosing a research method-focus group}

The qualitative research was conducted to fulfill the set goal, i.e. to find out what SMEs in the Czech Republic in terms of their running consider and perceive as contemporary data privacy issues in marketing and why. Specifically, a focus group was implemented. This method of qualitative research was chosen deliberately. This is preliminary research for future planned qualitative and quantitative research focused on changes in the approach of business entities in the Czech Republic to the protection of customers' personal data after the effectiveness of GDPR.

Although this research method has its limits, namely the fact that the results cannot be generalized, it was nevertheless chosen because it can provide greater insight into the 
researched issues from the perspective of practitioners who deal with it. The choice of this method is also not accidental, given the fact that the issue of GDPR is a very broad topic. The opinions and experiences of experts from practice can therefore greatly contribute to the concretization, expansion, or conversely, narrowing of the researched issues to those topics and areas that are perceived by them or considered from their point of view to be problematic, unclear, or whose solution is associated with certain challenges. The findings obtained on the basis of the focus group will be used for the next step of the planned research, specifically as a basis for the preparation of questions for a semi-structured interview and also as a basis for the preparation of a questionnaire for quantitative research.

The focus group should be approached as a research method aimed at using the time allotted to discuss pre-selected topics and issues. In accordance with Hendl (2005), the aim is not to expect that within the focus group its participants will reach either an agreement or a disagreement on the discussed topic. In order to fulfill the set goal, it is necessary to obtain qualitative data. According to Miovský (2006), the focus group is one of the most effective ways to collect qualitative data. And although there is the above-mentioned limitation in connection with the focus group, which is the impossibility of generalizing findings, there are also indisputable advantages, which are mentioned, for example, by Morgan (1996). It is a relatively short time for a focus group, approximately an hour and a half to two hours, and the opportunity to gain opinions and experiences on the topics discussed from different participants with different practical experience at the same time. Lindlof (2002) deals with the question of what is the ideal number of focus group participants. He believes that the ideal number is $6-8$ participants. At the same time, he states the reasons why not less and why not more participants. The participation of more than 8 people is directly proportionally related to the smaller time space for each of them to express the opinion on the issues discussed. On the contrary, with less than 6 participants, there is a risk that some exhaustion of useful and informative contributions from stakeholders in the discussion will occur more quickly.

Some authors (Agan et al. 2008) deal with the issue of ensuring the validity of such research. They express the opinion that in order to ensure validity, it is necessary to carry out $3-5$ focus group discussions within the research. In this context, Miovský (2006) says that the number of focus groups is not important, because it depends mainly on the quality of the obtained data. It is advisable to follow the saturation rule. In each individual case, it is, therefore, necessary to consider why the focus group is carried out and what purpose it intends to fulfill within the research process. The total number of focus groups will then depend on the answer to this question.

\section{Research focus and research participants}

The focus of the research was on GDPR in connection with the protection of personal data of customers and marketing. The aim was to find out what small and medium-sized businesses in the Czech Republic consider and perceive in terms of their running as current problematic issues concerning the protection of personal data of customers in marketing and why. This is due to the fact that marketing and personal data protection are among the areas that have been fundamentally affected by GDPR. The participants in the research were not only small and medium-sized enterprises, but also micro-enterprises with up to 10 employees. Deliberate targeting on micro, small, and medium-sized businesses in the Czech Republic was not accidental. According to the Report on the Development of the Business Environment in the Czech Republic in 2018, prepared by the Ministry of Industry and Trade, it is clear that the share of small and medium-sized enterprises in the total number of active business entities in 2018 was $99,83 \%$. 
The focus group was implemented in the second half of August this year. Micro, small and medium-sized businesses were evenly represented. The total number of participants was six. A total of 23 business entities were approached with a request to participate in the focus group. Five of them did not respond to the request, four business entities refused to participate due to time constraints. A total of 14 addressed business entities were willing to participate in the focus group, however, it was necessary to reduce this number so that the total final number of participants would allow a constructive discussion on selected topics and issues in the allotted time and especially sufficient time for each participant to express an opinion. Therefore, six participants were finally selected from this number, so that micro, small, and medium-sized business entities were evenly represented. The remaining business entities promised to participate in a future planned research.

The number of employees was the basic and decisive criterion for the classification of business entities into micro, small and medium-sized enterprises. Each participating business entity was represented in the focus group by a selected representative. It was either the owner of the business entity or the employee who is in charge of GDPR issues, marketing, or customer relationship management. Business entities were randomly approached to participate in the focus group. It was assumed that each business entity, regardless of whether it has a predominant $\mathrm{B} 2 \mathrm{C}$ or $\mathrm{B} 2 \mathrm{~B}$ relationships, has its customers with whom the business entity must communicate and whose data is collected by a business entity for different legal grounds for different purposes. Participants were between 29 and 56 years old. Men and women were equally represented. All participants had at least a high school education. Four of them also had a university degree. Five participants were in the position of an employee, only one participant was the owner of the business entity.

When asked about the motivation to participate in the research, the majority answered that they would welcome any opportunity to learn any new information on the topic of GDPR and also to share their own experiences and discuss these with other who have to solve and face similar problems. All participants also agreed that the issue of GDPR is still in some respects a challenge associated with perceived and continuing uncertainty as to whether their business is fully compliant or whether practice will show over time the shortcomings associated with the threat of sanctions. It can therefore be stated that the reasons for participation communicated by the participants are very close to those mentioned by Morgan (2001). He sees the main motivation for participating in the focus group in the opportunity that participants get and thanks to which they can not only share, but also compare their experiences on the topics and issues discussed.

\section{Data collection and the course of the focus group}

The length of the focus group was scheduled for an hour and a half. This time frame has been met. All participating business entities conditioned their participation in the focus group with anonymity. The focus group took place in the second half of August 2020. Participants were informed that the discussion will be audio-recorded at all times. The advantage is that the moderator of the discussion is not forced to write down literally everything that was said during the discussion. As Lindlov and Taylor (2002) point out, the mere fact that a discussion is audibly recorded can lead to some degree of self-control and greater caution about what and how participants say. The moderator's task is therefore to create an atmosphere of mutual trust by paying full attention to the discussants when expressing their views and attitudes. The participants were acquainted in advance with the topic of discussion and the researcher's intention to find out what SMEs in the Czech Republic in terms of their running consider and perceive as contemporary data privacy issues in marketing and why. 
After the focus group, the audio recordings were transcribed into written form. Subsequently, the analysis of the obtained qualitative data was performed. The information obtained from the individual participants was compared with each other and both similarities and differences were sought. During the discussion, pre-prepared questions were gradually asked. If the discussants deviated from the question, but their statement still touched on the topic in some way, enough space was left them by the moderator and also other participants if they wanted to add their opinion or comment on someone else's statement.

Subsequently, the findings that the participants mentioned most often and which were repeated in their statements or which were marked by some of them as important in terms of experience and running of their business entity are presented.

\section{Analysis and qualitative research results}

\subsection{Focus group theme and research questions}

The topic of the focus group was "Current issues of personal data privacy in marketing".

Two research questions were set for the focus group, namely:

1. What do SMEs in the Czech Republic perceive and consider in connection with their running as current issues and problems of customer personal data protection in marketing in connection with GDPR and why?

2. What and why do SMEs in the Czech Republic consider as benefits and negatives in relation to their activities in the field of marketing and protection of customers' personal data due to GDPR?

\subsection{Questions and topics for focus group}

With regard to the time limit of the focus group, 9 questions were prepared. The questions were deliberately divided into two groups. The main goal of the questions included in the first group was to find out whether the participants are aware of the issue and how long they have been working in the given area of interest. It was found that all participants must more or less address the issue of GDPR as part of their job responsibilities. The second group included questions aimed at answering the set research questions.

The following questions were included in the second group and were the main content of the discussion.

1. What is nowadays important for your business entity in relation to the customer?

2. Is there anything about GDPR that is unclear or problematic for your business entity, even after more than two years of its effectiveness?

3. What do you perceive as the biggest challenge for your business entity in connection with GDPR and how do you deal with it in practice?

4. What problems does your business entity perceive in relation to GDPR?

5. Can it be said that in connection with GDPR there are also some positive aspects for your business entity?

6. What are the benefits and negatives of GDPR to your business entity?

\subsection{Evaluation of questions}

Question no. 1: What is nowadays important for your business entity in relation to the customer? 
The aim of this question was to find out how business entities nowadays perceive the customers and what they consider important in relation to them. All participants confirmed that this as absolutely essential. Everyone also agreed that today's technology-rich era makes it relatively easy for customers to compare a wide range of product and service offerings. From the point of view of business entities, it is therefore very important to be able to address the target customers and subsequently be able to retain them. Everyone agreed that this is of course possible, but it requires both knowledge of the customers and their needs, communication with them, and to tailor the offer to the customer's needs. The participants agreed that customer satisfaction is important to them. That's why they try to personalize. They consider the ability to tailor a service or product to a specific customer to be a key aspect of achieving customer satisfaction. As one of the participants added, a satisfied customer very often becomes a loyal customer. All participants are of the opinion that in order to build relationships with customers, it is necessary to have a sufficient amount of information about them. As one of the participants literally said: "In today's highly competitive environment, there is no other way than to value and care for each customer, it is about creating and maintaining long-term relationships, without this it is simply not possible nowadays and this can differentiate us from the competition. Undoubtedly, it is also about the customer's trust in us and at the same time about our openness and transparency towards the customer". Participants acknowledged that sufficient customer information is important, but the customers are not always willing to provide their information. In this respect, building mutual trust is important and, as one participant emphasized, the customers must feel that if they provide their data, they will benefit from it.

Question no. 2: Is there anything about GDPR that is unclear or problematic for your business entity, even after more than two years of its effectiveness?

More than two years have passed since GDPR took effect. From this point of view, it could be concluded that the content of this regulation no longer poses any problems for business entities, because they had two years for implementation and for more than two years, they have to be in full compliance with the requirements of GDPR. The aim of this question was therefore to find out whether the mentioned time interval from the effectiveness of GDPR contributed to greater knowledge and understanding of the European legislation. In other words, whether the orientation in the issue of GDPR no longer causes difficulties for business entities and the requirements of GDPR are obvious, clear, and unproblematic for them. This question aroused great emotion and amusement among the participants at the same time. They all confirmed that although GDPR has been in force for more than two years, this period has certainly not contributed to a greater understanding and clarity of the regulation. The participants also agreed that at first sight GDPR may seem like clear and comprehensible rules, however, when trying to put these rules into practice, the questions may arise that are difficult to find answers to. One of the participants pointed out, for example, the incomprehensible situation related to the data subject's request to delete the data that the business entity has about him. The business entity is obliged to comply with such a request of the data subject for erasure if any of the reasons specified in GDPR occurs, e.g. 1) personal data are no longer needed for the purpose for which they were collected or processed (e.g. for contract performance - goods have already been delivered, the service has already been provided), 2) the data subject revokes the consent if the processing is based on consent and there is no other legal reason for processing, 3) the data subject objects to the processing performed by the controller due to the existence of legitimate interest on his part. However, as all participants confirmed, in the case of potential future disputes, the question is how the business entity should demonstrate that it has complied with the request and when it was done. This means for a business entity, that it must have a record that the data subject made this request, which exactly made the request for erasure when this request was made. However, the business entity will still have the data subject's identification 
in its record in order to be able to demonstrate, in the event of an inspection, that the data subject's request has been complied with without undue delay after its submission and that the business entity has therefore complied with the obligation imposed on it by GDPR. According to all participants, GDPR is still perceived by them as unclear and problematic in a number of respects; however, they hope that the procedures established by them are in line with the GDPR. They could only be sure of this in the light of the results of the inspection carried out by the inspection body, which would not find any error.

Question no. 3: What do you perceive as the biggest challenge for your business entity in connection with GDPR and how do you deal with it in practice?

All participants identified GDPR itself as the biggest challenge. The same or very similar views emerged. In particular, it has been said that although they are used to a number of pieces of legislation, which change frequently and which impose a number of obligations on them, in terms of GDPR they perceive the situation differently. They cited the threat of heavy sanctions as the main reason. One of the participants pointed out that even though no enormously high sanctions have been imposed in the Czech Republic so far, this situation cannot be relied on, rather it can be perceived as calm before the storm. All participants agreed that the only way to meet GDPR and the challenge it posed is to take all such measures that ensure on the one hand compliance with GDPR, on the other hand, that will be affordable for the business entity with regard to its financial and human resources. However, everyone acknowledged that ensuring compliance with GDPR is a financial and personnel burden, and each business entity must critically consider what it can afford in this regard in order to be so-called compliant.

Question no. 4: What problems does your business entity perceive in relation to GDPR?

In principle, all participants agreed that they perceive several problems. Most mentioned in the first place the feeling of lingering uncertainty as to whether they are in fact fully in line with GDPR. On the one hand, they are convinced that they have done everything needed and necessary to meet the requirements imposed on them by GDPR, on the other hand, they still perceive some degree of uncertainty and concern as to whether the measures set up by them and procedures put in place would be assessed in the same way by the inspection body. Five participants mentioned the human factor as a big problem. When asked why they specified that while they may establish procedures and precise rules in the organization on how to handle personal data and who will have access to what personal data, there is still a risk that the human factor, i.e. the employee, will fail negligently or intentionally. In its defense, the business entity can demonstrate that is has put in place the necessary measures and that employees are regularly trained in personal data protection and GDPR in general, but the truth is that all liability for any breach remains with the controller. When asked about a possible solution to outsource GDPR compliance to an external business entity, four participants stated that their organization had chosen this solution, but the responsibility remains with the controller when the measures taken will prove insufficient in the future. They gave insufficient personnel and knowledge capacities within their organization as a reason for the outsourced solution; even though this form of the solution was probably more expensive than if they ensured compliance with GDPR with their own human resources.

Question no. 5: Can it be said that in connection with GDPR, there are also some positive aspects for your business entity?

The answer to this question was surprisingly very similar from all involved. There was general agreement that it is very difficult to talk about any elements with a positive impact on the running of the organization. As one of the participants emphasized, it is necessary to take into account the simple fact that GDPR aims to protect the personal data of individuals and that this 
is indeed only a number of new obligations for the business entity, whether in relation to the personal data of customers or employees. All the discussants also pointed out that the obligation to ensure compliance more or less distracts them over time from their main business activity, which is absolutely crucial for them, as it provides them with an income and on which they need to focus in the first place.

\section{Question no. 6: What are the benefits and negatives of GDPR to your business entity?}

It is interesting that the participants only talked about the negatives, they did not mention any positives. When asked if they would find some positive aspects regarding GDPR, they said that they were forced to do something like an audit of personal data and their flow within the organization, which gave them a better awareness what data and to what extent are collected by the organization and then to consider their real need. However, as they added, the question is whether this can be perceived as a positive aspect because this activity was associated with a great time and therefore financial demands. In connection with GDPR, several perceived negatives were mentioned by the participants. Specifically, for example, other costs that could be used much better for the development of the business entity, the problem of finding a qualified workforce well-oriented about GDPR issues, the need to provide regular quality training for employees who come into contact with personal data, the danger of human failure, which is very difficult to avoid, rather impossible and last but not least, GDPR as a possible tool for unfair competition in the form of allegations of non-compliance with GDPR.

\subsection{Summary of results}

An overview of the research questions and the main results for each of them is given in the following table (Tab. 1).

Table 1: The overview of research questions and main results for each of them

\begin{tabular}{|c|c|}
\hline \multicolumn{2}{|c|}{ Focus group theme: Current issues of personal data privacy in marketing } \\
\hline $\begin{array}{l}\text { Research question 1: What do SMEs in the Czech Republic } \\
\text { perceive and consider in connection with their running as } \\
\text { current issues and problems of customer personal data } \\
\text { protection in marketing in connection with GDPR and why? }\end{array}$ & $\begin{array}{l}\text { Research question 2: What and why do SMEs in the Czech } \\
\text { Republic consider as benefits and negatives in relation to their } \\
\text { activities in the field of marketing and protection of customers' } \\
\text { personal data due to GDPR? }\end{array}$ \\
\hline $\begin{array}{l}\text { Q1 - What is nowadays important for your business entity } \\
\text { in relation to the customer? } \\
\text { - a long-term relationship with customers } \\
\text { - satisfied customer } \\
\text { - to know the customer and his/ her needs } \\
\text { - to create customer confidence in the business entity } \\
\text { - open and transparent approach to the customer (e.g. clear and } \\
\text { comprehensible data policies) } \\
\text { Q2 - Is there anything about GDPR that is unclear or } \\
\text { problematic for your business entity, even after more than } \\
\text { two years of its effectiveness? } \\
\text { - lack of clarity and persistent ambiguity of some provisions }\end{array}$ & $\begin{array}{l}\text { Q5 - Can it be said that in connection with GDPR there are } \\
\text { also some positive aspects for your business entity? } \\
\text { - no, only a number of new obligations } \\
\text { Q6 - What are the benefits and negatives of GDPR to your } \\
\text { business entity? } \\
\text { - benefit in the form of an overview and knowledge of what data } \\
\text { and to what extent are collected - balanced by a negative in the } \\
\text { form of time and financial requirements } \\
\text { - negatives: 1) financial expenses, 2) lack of qualifies workforce } \\
\text { familiar with GDPR issues, 3) the need for regular training of } \\
\text { employees on GDPR issues, 4) the still present risk of human } \\
\text { failure, human error, 5) a possible tool for unfair competition }\end{array}$ \\
\hline $\begin{array}{l}\text { Q3 - What do you perceive as the biggest challenge for } \\
\text { your business entity in connection with GDPR and how do } \\
\text { you deal with it in practice? } \\
\text { - GDPR itself } \\
\text { - the threat of heavy sanctions } \\
\text { - to take the necessary measures in view of the nature and } \\
\text { quantity of the data processes (a problem of limited available } \\
\text { financial and human resources) }\end{array}$ & \\
\hline $\begin{array}{l}\text { Q4 - What problems does your business entity perceive in } \\
\text { relation to GDPR? } \\
\text { - the feeling of lingering uncertainty whether the full } \\
\text { compliance was really met } \\
\text { - human factor (employee) as a potential source of risk }\end{array}$ & \\
\hline
\end{tabular}

Source: own research 


\section{Discussion}

It can be stated that the qualitative data obtained on the basis of the focus group confirmed the finding presented in the literature review and theoretical background. Specifically, it can be said that the importance of customers' personal data perceived by participants and their use for personalization of offers corresponds to the views of, for example, Martin et al. (2017), Aquirre et al. (2015), Tam et al. (2006) and others cited. The above-mentioned theories concerning privacy and marketing are reflected in the mindset of business entities in the sense of their perception of the importance of the customer's position in mutual marketing exchange. The aim is to create and maintain long-lasting relationships that benefit not only business entities but also customers. Therefore, it is necessary that there are mutual trust, communication, a feeling on the part of the customers that the provision of their personal data will be of benefit to them, for example in terms of the personalized offer or favorable price. The task of a business entity is to create an environment that will promote trust, not only through personal data protection policies but also through real behavior towards the customers.

\section{Conclusion}

The aim of this paper was to find out and then present what SMEs in the Czech Republic consider and perceive in terms of their running as contemporary data privacy issues in marketing and why. Marketing and protection of customers' personal data are areas that have been fundamentally affected by GDPR. The issue of GDPR is very broad and, above all, this regulation does not give clear and unambiguous instructions to business entities on how to behave or what exactly to do in order to comply with this European legislation. Therefore, the aim of qualitative research was to find out the opinions and experiences of experts from practice, which will contribute to the concretization, narrowing, or expansion of the research area. Qualitative research was carried out in the form of a focus group. The choice of this research method was justified. At the same time, certain limitations of this method were stated, namely the impossibility to generalize the obtained results. Therefore, it was explained what the focus group's goal is. The qualitative research presented in this paper is perceived as a preresearch and it is already the second focus group in a row. The information obtained will serve as a basis for future planned qualitative research, which will be carried out in the form of indepth semi-structured interviews with experts from practice, as well as for future quantitative research, which will be carried out in the form of a questionnaire. These planned researches will be conducted as a part of the author's doctoral study.

From the results of the focus group, it is clear that business entities are very well aware of the importance of the customer as a key element for the success of their business. All participants are aware of the growing competition due to the ever-evolving technological progress. Therefore, they perceive the importance of knowing the customers and their needs and the closely related ability to personalize offers. A satisfied customer is a basis for long-lasting relationships and together with the openness and transparency provided by the business entity, all this contributes to creating customer confidence in the business entity. And all this affects the willingness of customers to provide their data to a business entity. Surprisingly, the participants mostly agreed on what they perceive as current issues of personal data privacy in marketing. This is mainly a lack of clarity and fact that some ambiguities still remain. Even two years after the effectiveness of GDPR, they see this regulation as a challenge, because they are not entirely sure whether the procedures, they put in place are indeed fully in line with GDPR and therefore still perceive the threat of heavy sanctions. The participants stated that their business entities had taken the measures, but emphasized at the same time that there was a limitation of financial and human resources in this sense. During the discussion, they also 
agreed that the human factor is still a potential source of risk in the form of data leakage for them and that it is very difficult to ensure that this does not happen, if not impossible.

Interestingly, in the context of GDPR, none of the participants sees any positives, only a number of obligations. Although it was said that due to the need to audit personal data and their flow within the organization, on the one hand, they have a better overview in this regard, but on another hand, they were not sure whether it could be described as a positive aspect, because it was associated with great financial and time requirements for them. With regard to the negatives, several were mentioned by them, such as financial expenditure, lack of skilled GDPR staff, the need for regular staff training, still present risk of human failure, GDPR as a possible tool for unfair competition.

These results presented in the paper should be seen in terms of preliminary research and as a basis for future qualitative and quantitative research, as mentioned above. With this in mind, the conditions for the applicability of these results, as well as certain limitations and obstacles to their research and practical implications, need to be taken into account. The results of the focus group are a summary of the research participants' own practical experiences and opinions. The aim of the focus group is not to reach an agreement between the participants; however, there is the same or at least very similar opinion on a number of topics. The findings showed, among other things, that the topic of personal data privacy in marketing can be perceived and understood in a broader context, as this issue affects a number of activities of business entities. Therefore, the planned case studies are found to be very useful for a better and clearer understanding of the problems mentioned by the participants within the preliminary research, as well as for mediating possible solutions and their impacts, which can serve as an inspiration to other business entities in finding their own optimal solution.

To sum up, the results of the preliminary research provide information which, in terms of practical impacts and consequences for business entities, confirm the continuing topicality of GDPR issues and at the same time the need to deal with perceived negatives. The business entities realize the importance and significance of long-term customer relationships for their business. In this regard, the results of the preliminary research show that the negatives presented by the focus group participants are also challenges that every business entity has to deal with in the long run and must try to transform them to a positive level, which will be reflected not only in the successful acquisition of new, but also, in particular, the retention of existing customers. This is associated with the creation of higher loyalty and profitability of these customers. Ultimately, this will result in higher profitability for the business entity. As already mentioned the results of the preliminary research will serve as a basis and starting point for future qualitative and quantitative research. Specifically, future research will cover changes in the access of business entities in the Czech Republic to personal data of customers as a result of the implementation of GDPR and the impact of these changes on CRM (customer relationship management). The method of case studies will be used in the qualitative research. Data collection will be carried out by conducting semi-structured in-depth interviews. The planned quantitative research will be carried out in the form of a questionnaire and its aim will be to confirm or refuse the established hypotheses, which will contribute to solving of the research problem. In this way, for example, it will be ascertained whether a change in data protection policies due to GDPR leads to a greater willingness of customers to share their personal data.

Thanks to the knowledge gained through the focus group, it is therefore possible to better target and set up future research. 


\section{References}

[1] AGAN, J. et al., 2008. The Use of Focus Groups in Rehabilitation Research. Journal of Prevention, Assessment \& Rehabilitation, 31(2), 259 - 269.

[2] AGUIRRE, E. et al., 2015. Unravelling the Personalization Paradox: The Effect of Information Collection and Trust Building Strategies on Online Advertisement Effectiveness. Journal of Retailing, 91(1), pp. 34- 49. Doi: 10.1016/j.jretai.2014.09.005.

[3] ANSARI, A. and C. F. MELA, 2003. E-Customization. Journal of Marketing Research, 40 (2), $131-145$.

[4] ASHWORTH, L. and C. FREE, 2006. Marketing Dataveillance and Digital Privacy: Using Theories of Justice to Understand Consumers' Online Privacy Concerns. Journal of Business Ethics, 67(2), 107 - 123.

[5] BLEIER, A. and M. EISENBEISS, 2015. The Importance of Trust for Personalized Online Advertising. Journal of Retailing, 91(3), 390-409.

[6] BREHM, J. W., 1966. A theory of psychological reactance. Oxford, England: Academic Press.

[7] CAUDILL, E. M. and P. E. MURPHY, 2000. Consumer Online Privacy: Legal and Ethical Issues. Journal of Public Policy \& Marketing, 19(1), 7 - 19.

[8] EMERSON, R. M., 1976. Social Exchange Theory. Annual Review of Sociology, 2, 335 362.

[9] EUROPEAN PARLIAMENT AND THE COUNCIL, 2016. Regulation (EU) 2016/679 of the European Parliament and of the Council of 27 April 2016 on the protection of natural persons with regard to the processing of personal data and on the free movement of such data, and repealing Directive 95/46/ES (General Data Protection Regulation).

[10] EUROPEAN PARLIAMENT AND THE COUNCIL, 1995. Directive 95/46/EC of the European Parliament and of the Council of 24 October 1995 on the protection of individuals with regard to the processing of personal data and on the free movement of such data.

[11] HENDL, J., 2005. Kvalitativní výzkum: základní metody a aplikace. Praha. Portál.

[12] CHELLAPPA, R. K. and R. G. SIN, 2005. Personalization versus Privacy: An Empirical Examination of the Online Consumer's Dilemma. Information Technology and Management, 6(2), $181-202$.

[13] LINDLOF, T. R. and C. T. BRYAN, 2002. Qualitative Communication Research Methods. SAGE Publication, Inc.

[14] LWIN, M. et al., 2007. Consumer Online Privacy Concerns and Responses: A PowerResponsibility Equilibrium Perspective. Journal of the Academy of Marketing Science, 35(4), $572-585$.

[15] MAIGNAN, I. and O. C. FERRELL, 2004. Corporate Social Responsibility and Marketing: An Integrative Framework. Journal of the Academy of Marketing Science, 32(1), $3-19$.

[16] MARTIN, D. K. and M. E. MURPHY, 2017. The Role of Data Privacy in Marketing, Journal of the Academy of Marketing Science, 45(2), 135 - 155. DOI 10.1007/s11747016-049. 
[17] MINISTERSTVO PRŮMYSLU A OBCHODU ČESKÉ REPUBLIKY, 2019. Zpráva o vývoji podnikatelského prostředí v České republice v roce 2018. Published in November on 28, 2019. Retrieved in August on 14, 2020 from https://www.mpo.cz/cz/podnikani/male-a-stredni-podnikani/studie-a-strategickedokumenty/zprava-o-vyvoji-podnikatelskeho-prostredi-v-ceske-republice-v-roce-2018-251001 .

[18] MIOVSKÝ, M., 2006. Kvalitativni př́stup a metody v psychologickém výzkumu. Praha: Grada Publishing. ISBN 80-247-1362-4.

[19] MORGAN, D. L., 1996. Focus Groups. Annual Review of Sociology, 22(1), 129 - 152.

[20] MORGAN, D. L., 2001. Ohniskové skupiny jako metoda kvalitativního výzkumu. Boskovice: Albert.

[21] MURPHY, P. E. et al., 2005. Ethical Marketing. Upper Saddle River, NJ: Pearson.

[22] MURTHI, B. P. S. and S. SARKAR, 2003. The Role of the Management Sciences in Research on Personalization, Management Science, 49(10), 1344 - 1362.

[23] NORBERG, P. A. and D. R. HORNE, 2014. Coping with Information Requests in Marketing Exchanges: An Examination of Pre-post Affective and Behavioral Coping. Journal of the Academy of Marketing Science, 42(4), 415 - 429.

[24] RAWLS, J., 1971. A theory of justice. Cambridge, MA: Harvard University Press.

[25] ROSSI, P. E. et al., 1996. The Value of Purchase History Data in Target Marketing, Marketing Science, 15(4), 321 - 340.

[26] RUST, R. T. and T. S. CHUNG, 2006. Marketing Models of Service and Relationships. Marketing Science, 25(6), 560 - 580.

[27] SCHULTZ, R., 2018. A Gentleman's C: Email Marketers Grade Themselves on Personalization. Available from: https://www.mediapost.com/publications/article/318211/a-gentlemans-c-emailmarketers-grade-themselves.html. Retrieved: 20. 09. 2020.

[28] SCHUMANN, J. H. et al., 2014. Targeted Online Advertising: Using Reciprocity Appeals to Increase Acceptance Among Users of Free Web Services. Journal of Marketing, 78(1), $59-75$.

[29] SUNDAR, S. S. and S. S. MARATHE, 2010. Personalization versus Customization: The importance of Agency, Privacy, and Power Usage. Human Communication Research, 36 (3), $298-322$.

[30] TAM, K. Y. and S. Y. HO, 2006. Understanding the Impact of Web Personalization on User Information Processing and Decision Outcomes. MIS Quarterly, 30(4), 865 - 890.

[31] VAIL, M. W. et al., 2008. An Empirical Study of Consumer Perceptions and Comprehension of Web Site Privacy Policies. IEEE Transactions on Engineering Management, 55(3), $442-454$.

[32] VERHOEF, P. C. et al., 2010. CRM in Data-Rich Multichannel Retailing Environments: A Review and Future Research Directions. Journal of Interactive Marketing, 24(2), 121 137.

[33] VESANEN, J., 2007. What is Personalization? A Conceptual Framework. European Journal of Marketing, 41(5/6), $409-418$. 
[34] WHITE, T. B., 2004. Consumer Disclosure and Disclosure Avoidance: a Motivational Framework. Journal of Consumer Psychology, 14(1\&2), 41 - 51.

[35] WHITE, T. B. et al., 2008. Getting too Personal: Reactance to Highly Personalized Email Solicitations. Marketing Letter, 19(1), 40 - 50.

[36] XU, H. et al., 2012. Effects of Individual Self-protection, Industry Self-regulation, and Government Regulation of Privacy Concerns: A Study of Location-based Services. Information Systems Research, 23(4), 1342 - 1363.

[37] ZHANG, J. and M. WEDEL, 2009. The Effectiveness of Customized Promotions in Online and Offline Stores. Journal of Marketing Research, 46(2), 190 - 206.7. 